\title{
E-cadherin germline mutations in Māori population
}

\author{
Alessandra Margherita De Scalzi ${ }^{1}$, Bernardo Bonanni ${ }^{2}$, Viviana Galimberti ${ }^{1}$, Paolo \\ Veronesi ${ }^{1,3}$, Gabriella Pravettoni ${ }^{3,4}$ \& Giovanni Corso*,1,3 \\ ${ }^{1}$ Division of Breast Surgery, European Institute of Oncology IRCCS, 20141 Milan, Italy \\ ${ }^{2}$ Division of Cancer Prevention \& Genetics, European Institute of Oncology IRCCS, 20141 Milan, Italy \\ ${ }^{3}$ Faculty of Medicine, University of Milan, Italy \\ ${ }^{4}$ Applied Research Division for Cognitive and Psychological Science, European Institute of Oncology, 20141 Milan, Italy \\ *Author for correspondence: Tel.: +39 0294375161; giovanni.corso@ieo.it
}

\section{'The results of $C D H 1$ screening in the Māori are in marked contrast with findings from other GC patients."}

First draft submitted: 4 November 2018; Accepted for publication: 27 February 2019; Published online: 12 April 2019

Keywords: E-cadherin $\bullet$ gastric cancer $\bullet$ hereditary cancer

$\mathrm{CDH1}$ germline alterations are notoriously responsible for the development of hereditary diffuse gastric cancer (HDGC), an inherited autosomal cancer syndrome. Discovered for the first time in New Zealand in three Māori kindred, several $C D H 1$ alterations have also been identified in different ethnic populations to date. These mutations affect, with high frequency, areas with otherwise low incidence of gastric carcinoma (GC), as well as the Māori population. In this brief review, we report and describe the $C D H 1$ germline mutations recognized in this ethnicity.

\section{GC incidence}

GC is the fourth most common cancer worldwide, with about 934,000 new cases per year ( $8.6 \%$ of new cases of tumor per year) as estimated in 2002, after lung, breast and colorectal. GC is the second leading cause of cancerrelated death, with 700,000 deaths annually. The incidence is significantly higher in less developed countries, with $42 \%$ represented by China alone. There is a wide variation in the distribution of GC between different areas of the world: high-risk areas include East Asia (China, Japan and Korea), Eastern Europe and parts of Central and South America. In Southern Asia, North and East Africa, North America, Australia, New Zealand and Africa the incidence rates are low ( $<10$ per 100,000 in men) [1].

In Europe, GC is the fifth most common cancer, after colorectal, breast, lung and prostate, with an incidence of 149,000 new cases per year and a mortality rate of 116,000 per year. Eastern Europe is the area with the highest incidence of GC with 70,000 new cases per year just in the Belarus area [2].

\section{The Māori ethnic group}

The ancestors of the Māori were indigenous Polynesian people from Southeast Asia. They traveled by sea with typical canoes to New Zealand between 1250 and 1300 and for many centuries they lived in isolated communities. Thanks to this condition and due to New Zealand's distance from other landmasses, they developed peculiar culture, traditions, language and religion, distinguishing this tribal group from any other.

Nowadays the Māori ethnicity is a consistent part of New Zealand population; in 2010 it was estimated to be around the 15\% (more or less 660,000 individuals) and the te reo, the Māori language, is one of the New Zealand's official languages since 1987 , spoken by about $3.7 \%$ of the population.

A higher incidence of GC in Māori population was recognized in 1964 by Jones [3]. After examining this ethnic group for 30 years, it was observed that gastric cancer affected and led to death of over 25 family members. The first family tree under examination was composed of 98 members, 28 (28.6\%) of which developed a primary GC and two a colon cancer. Contrary to what might be expected, the incidence of different kind of cancers in this 
family was average. Fourteen years-old was the earliest death reported in series, but the majority of deaths occurred before age of 40 .

Among the 28 cases of gastric cancer, the distribution in gender was equivalent: 14 males and 14 females, with a mean age at diagnosis of respectively 36 and 31 years, showing a lower age of disease onset in females. The overall mean age at onset was 34 years. These data show a wide difference with general population in New Zealand, in which about the $80 \%$ of GCs occur in people over 60 years of age.

Data about the annual incidence of GC among New Zealand population are available online on the government website [4]. In this annual report, the population is split into Māori and non-Māori and it gives the opportunity to observe a significant increase in incidence in Māori of both sexes since 2000, in contrast with incidence rates in the non-Māori population which continued to uniformly decline [5].

\section{E-cadherin germline mutations}

A pathogenic CDH1 mutation is estimated to be present in about $40 \%$ of families with HDGC (defined as families from low-incident populations with two or more cases of gastric cancers with at least one proven DGC diagnosed in an individual before age 50) [6]. Oliveira et al. [7] indicated that germline CDH1 point or small frameshift mutations can be found in $30-50 \%$ of HDGC families.

The penetrance of HDGC is approximately $70 \%$ in CDH1 mutation carriers $[6,8]$.

Women with a mutation in CDH1 and members of HDGC families have a lifetime risk of roughly $40 \%$ to develop a breast lobular carcinoma $[9,10]$.

The $C D H 1$ germline mutation is the sine qua non of getting the diagnosis of HDGC. In 2010, the International Gastric Cancer Linkage Consortium published updated recommendations [11] for genetic testing, surgery, endoscopy and pathology for HDGC with CDH1 mutations. Currently, genetic test criteria consider individuals diagnosed with DGC before the age of 40 years even if there is no family history. A test should also be performed in families with diagnoses of both DGC and lobular breast cancer, if at least one person has the onset before the age of 50 years. Testing is considered appropriate from the age of the consent. Before the genetic test, it is required to have an appropriate counseling and a discussion with the multidisciplinary team. A recognized CDH1 mutation in women increased the risk of developing a lobular breast cancer (LBC) and an annual mammography and breast MRI should be performed from the age of 35 .

The CDH1 germline mutation carriers with a diagnosis of LBC have a high risk of HDGC syndrome [9]. Vice versa, an early onset of LBC might be the first presentation of HDGC.

Benusiglio et al. [12] identified CDH1 germline deleterious mutations in three bilateral LBC cases (age at onset $<50$ years) not fulfilling the International Gastric Cancer Linkage Consortium criteria.

These families have no history of HDGC in first- and second-degree relatives and no BRCA1 and BRCA2 mutations. In another series reported by Petridis, five CDH1 mutations have been identified in four bilateral early onset LBCs (age at onset $<50$ years) with no family history for HDGC [13]. Furthermore, Silva et al. reported two female patients with LBC (ages 60 and 51), both carriers of germline CDH1 mutations, who underwent prophylactic gastrectomy that revealed foci of intramucosal DGC in both cases [14].

Very recently, two potentially pathogenic CDH1 alterations were reported in patients with LBC without a family history of gastric tumor $[15,16]$. Considering only individuals with LBC and excluding genealogical chart with gastric tumor occurrence, a total of 495 female LBCs from six independent original studies were screened for $\mathrm{CDH} 1$ genetic alterations. Sixteen (3.2\%) novel $\mathrm{CDH} 1$ germline variants have been identified. Bilateral LBC was diagnosed in $14.3 \%$ of cases $(6 / 63)$, positive family history for BC was reported in $40.3 \%$ and the mean age at onset was about 45 years-old [17].

DGC lesions are submucosal and the screening with endoscopy with multiple biopsies are inadequate for early diagnosis [18]. A possible diagnostic delay and the high mortality rate made the prophylactic total gastrectomy a viable option for mutation carriers $[8,19,20]$. The prophylactic surgery should be strongly evaluated in centers of excellence. As every prophylactic surgery, also the choice of a total gastrectomy may be an extremely problematic emotional experience [20-22] and a compassionate genetic counseling should be guaranteed.

For the $\mathrm{CDH} 1$ pathogenic mutation carriers that refuse the option of a prophylactic surgery, a strictly endoscopic surveillance at centers of expertise is highly recommended. In the same way also all the patients who have genetical modification of undetermined significance and all the members of families in which a germline mutation has not yet been identified should be controlled every year [23]. 


\section{E-cadherin genetic screening in Māori population}

In 1998, Guilford et al. first detected three different germline mutations in CDH1 gene in three Māori families from New Zealand. In those families with a high incidence of DGC were found a splice site $(\mathrm{OO} 0 \mathrm{BG}>\mathrm{T})$, a frameshift (238 2- 238 6, Cins) and a premature termination (TAG, 2095C > T) germline mutation in the $\mathrm{E}$ cadherin gene [24], respectively.

In 1999, the International Gastric Cancer Linkage Consortium defined this predisposition as HDGC [25]. Other international studies subsequently identified novel $C D H 1$ germline alterations in families Māori-unrelated. Notably, the majority of these pathogenic $C D H 1$ germline alterations 'affect' some countries otherwise classified as low risk for GC, as well as New Zealand, with higher frequency [26]. Thus, environmental factors, such as food consumption and lifestyle habits, have been investigated in association to stomach carcinogenesis and tumor development in countries with high incidence of GC [27].

In a recent study by Hakkaart et al. [28], $17 \mathrm{CDH1}$ germline alterations were identified in 94 Māori individuals with GC (18\%), with $34 \%$ of them diagnosed with HDGC, one of the highest frequencies ever reported in literature.

In details, five pathogenic alterations (three nonsense, one frameshift and one missense) were identified. The three nonsense mutations (190C $>$ T, $1792 \mathrm{C}>\mathrm{T}$ and $2287 \mathrm{G}>\mathrm{T}$ ) and one frameshift mutation (2381_2386insC) were identified in four cases each, while the deleterious missense mutation $(2195 \mathrm{G}>\mathrm{A})$ was identified in a single case.

The nonsense and frameshift mutations had already been identified previously in Māori families in New Zealand [29]. 2195G $>\mathrm{A}$ is a splice siting alteration that creates a new acceptor splice site and a large deletion in the E-cadherin protein, identified in a family from the UK with HDGC diagnosis [30]. 2195G > A had previously been detected in two families of northern European origin with HDGC [31]. Finally, 2195G>A was reported for the first time in New Zealand Māori population.

\section{Conclusion}

The results of $C D H 1$ screening in the Māori are in marked contrast with findings from other GC patients. In fact, incidence of CDH1 germline mutations is higher in the Māori in comparison with other ethnicities. New Zealand is considered a low-risk GC area and frequency of E-cadherin germline alterations is rather high, while in high risk GC areas $\mathrm{CDH} 1$ germline mutations are rarely identified. It is reasonable to imply that $C D H 1$ pathogenic germline alterations are strong contributors to the high frequency of HDGC in countries with low incidence of gastric carcinoma, as well in Māori population.

Financial \& competing interests disclosure

This manuscript was supported by the Italian Ministry of Health (project code: GR-2016-02361655. "Understanding how CDH1 germline mutations affect hereditary lobular breast cancer"). The authors have no other relevant affiliations or financial involvement with any organization or entity with a financial interest in or financial conflict with the subject matter or materials discussed in the manuscript apart from those disclosed.

No writing assistance was utilized in the production of this manuscript.

\section{References}

1. Jemal A, Bray F, Center MM, Ferlay J, Ward E, Forman D. Global cancer statistics. CA Cancer J. Clin. 61(2), 69-90 (2011).

2. Ferlay J, Parkin DM, Steliarova-Foucher E. Estimates of cancer incidence and mortality in Europe in 2008. Eur. J. Cancer 46(4), 765-781 (2010).

3. Jones EG. Familial gastric cancer. NZ Med. J. 63, 287-296 (1964)

4. Ministry of Health. Cancer: new registrations and deaths. Annual reports 1995-2009. New Zealand Ministry of Health, Wellington, New Zealand (2012). www.health.govt.nz

5. Arnold M, Moore SP, Hassler S, Ellison-Loschmann L, Forman D, Bray F. The burden of stomach cancer in indigenous populations: a systematic review and global assessment. Gut 63(1), 64-71 (2014).

6. Kaurah P, MacMillan A, Boyd N et al. Founder and recurrent CDH1 mutations in families with hereditary diffuse gastric cancer. JAMA 297(21), 2360-2372 (2007).

7. Oliveira C, Senz J, Kaurah P et al. Germline CDH1 deletions in hereditary diffuse gastric cancer families. Hum. Mol. Genet. 18(9), 1545-1555 (2009). 
8. Ziogas D, Roukos DH. CDH1 testing: can it predict the prophylactic or therapeutic nature of total gastrectomy in hereditary diffuse gastric cancer?. Ann. Surg. Oncol. 16(10), 2678-2681 (2009).

9. Keller G, Vogelsang H, Becker I et al. Diffuse type gastric and lobular breast carcinoma in a familial gastric cancer patient with an E-cadherin germline mutation. Am. J. Pathol. 155(2), 337-342 (1999).

10. Schrader KA, Masciari S, Boyd N et al. Hereditary diffuse gastric cancer: association with lobular breast cancer. Fam. Cancer 7(1), 73-82 (2008).

11. Fitzgerald RC, Hardwick R, Huntsman D et al. International Gastric Cancer Linkage Consortium. Hereditary diffuse gastric cancer: updated consensus guidelines for clinical management and directions for future research. J. Med. Genet. 47(7), 436-444 (2010).

12. Benusiglio PR, Malka D, Rouleau E et al. $\mathrm{CDH} 1$ germline mutations and the hereditary diffuse gastric and lobular breast cancer syndrome: a multicentre study. J. Med. Genet. 50(7), 486-489 (2013).

13. Petridis C, Shinomiya I, Kohut K et al. Germline CDH1 mutations in bilateral lobular carcinoma in situ. Br. J. Cancer 110(4), 1053-1057 (2014).

14. Silva R, Susy C, Carneiro F, Amendoira I. Genetic profile and morphological features of breast cancers in setting of hereditary breast cancer (HBC) syndrome. Virchows Arch. 2013(463), 101-352 (2013).

15. Stuebs F, Heidemann S, Caliebe A, Mundhenke C, Arnold N. CDH1 mutation screen in a BRCA1/2-negative familial breast-/ovarian cancer cohort. Arch. Gynecol. Obstet. 297(1), 147-152 (2018).

16. Corso G, Bonanni B, Veronesi P, Galimberti V. Mutual exclusion of CDH1 and BRCA germline mutations in the pathway of hereditary breast cancer. Arch. Gynecol. Obstet. 297(4), 1067-1068 (2018).

17. Corso G, Figueiredo J, Biffi R et al. E-cadherin germline mutation carriers: clinical management and genetic implications. Cancer Metastasis Rev. 33(4), 1081-1094 (2014).

18. Alberts SR, Cervantes A, van de Velde CJ. Gastric cancer: epidemiology, pathology and treatment. Ann. Oncol. 14(Suppl. 2), ii31-ii36 (2003).

19. Huntsman DG, Carneiro F, Lewis FR et al. Early gastric cancer in young, asymptomatic carriers of germ-line E-cadherin mutations. $N$. Engl. J. Med. 344(25), 1904-1909 (2001).

20. Lynch HT, Kaurah P, Wirtzfeld D et al. Hereditary diffuse gastric cancer: diagnosis, genetic counseling, and prophylactic total gastrectomy. Cancer 112(12), 2655-2663 (2008).

21. Kaurah P, MacMillan A, Boyd $\mathrm{N}$ et al. Founder and recurrent $\mathrm{CDH} 1$ mutations in families with hereditary diffuse gastric cancer. JAMA 297(21), 2360-2372 (2007).

22. Lynch HT, Grady W, Suriano G, Huntsman D. Gastric cancer: new genetic developments. J. Surg. Oncol. 90(3), 114-133; discussion 133 (2005).

23. Pedrazzani C, Corso G, Marrelli D, Roviello F. E-cadherin and hereditary diffuse gastric cancer. Surgery 142(5), $645-657$ (2007).

24. Guilford P, Hopkins J, Harraway J et al. E-cadherin germline mutations in familial gastric cancer. Nature 392(6674), 402-405 (1998).

25. Caldas C, Carneiro F, Lynch HT et al. Familial gastric cancer: overview and guidelines for management. J. Med. Genet. 36(12), 873-880 (1999).

26. Corso G, Marrelli D, Pascale V, Vindigni C, Roviello F. Frequency of CDH1 germline mutations in gastric carcinoma coming from high- and low-risk areas: metanalysis and systematic review of the literature. BMC Cancer 12, 8 (2012).

27. Palli D, Russo A, Ottini L et al. Red meat, family history, and increased risk of gastric cancer with microsatellite instability. Cancer Res. 61(14), 5415-5419 (2001).

28. Hakkaart C, Ellison-Loschmann L, Day R et al. Germline CDH1 mutations are a significant contributor to the high frequency of early-onset diffuse gastric cancer cases in New Zealand Māori. Fam. Cancer 18(1), 83-90 (2019).

29. Hansford S, Kaurah P, Li-Chang H et al. Hereditary diffuse gastric cancer syndrome: CDH1 mutations and beyond. JAMA Oncol. 1(1), 23-32 (2015).

30. Kaurah P, MacMillan A, Boyd N et al. Founder and recurrent CDH1 mutations in families with hereditary diffuse gastric cancer. JAMA 297(21), 2360-2372 (2007).

31. Brooks-Wilson AR, Kaurah P, Suriano G et al. Germline E-cadherin mutations in hereditary diffuse gastric cancer: assessment of 42 new families and review of genetic screening criteria. J. Med. Genet. 41(7), 508-517 (2004). 